\title{
Clinicopathological Profile of Ca Stomach and Comparison of Preoperative Findings with Peroperative and Histopathological Findings
}

\author{
S. Das ${ }^{1}$, A. Das $^{2}$ \\ ${ }^{1}$ Department of General Surgery, IPGMER, Kolkata, West Bengal, India. \\ ${ }^{2}$ Department of General Surgery, IPGMER, Kolkata, West Bengal, India.
}

\section{ABSTRACT}

\section{BACKGROUND}

Gastric cancer has been one of the leading causes of cancer-related mortality over the past century. Today it is the $4^{\text {th }}$ most common cancer in the world. Surgery remains the only major curative option. Majority of these cancers are found to be unresectable on laparotomy. It is also frequently seen that patients with a preoperatively resectable cancer as per a staging CT-Scan of the abdomen are found to have unresectable disease on laparotomy. In this study, we are trying to assess the clinico-pathological profile of gastric cancer and tally the preoperative radiological findings with the peroperative and final histopathological findings.

\section{METHODS}

It is a short-term prospective, observational study. 50 patients with gastric cancer permitted surgical intervention were prepared, operated, followed-up and preoperative, peroperative and final histopathological findings were tallied.

\section{RESULTS}

50 patients with gastric cancer were studied. The maximum age was 76 years and minimum age was 23 years with a mean age of 49.12 years with a standard deviation of 13.9776. Peak incidence was found in the age group of 41-60 years. $54 \%$ of the patients were male and $46 \%$ were female. The most common symptom was anorexia (94\%, z-value 8.8) followed by weight loss (86\%, z-value 7.2 ). The most common sign was anaemia which was present in $80 \%$ of the patients (z-value 6.0). $64 \%$ of the patients had intestinal type while $36 \%$ had diffuse type of gastric cancer. Patients with diffuse type were $<50$ years of age. Diffuse type was more common in females while intestinal type was more common in males. The accuracy of T, N, M staging on preoperative CT-Scan tallied with peroperative findings is $44 \%$, $38 \%$ and $72 \%$ respectively. $44 \%$ of the patients underwent a palliative surgical procedure, of which $90.9 \%$ had poorly-differentiated and $9.1 \%$ had moderatelydifferentiated cancer.

\section{CONCLUSIONS}

Preoperative CT-Scan may not be a very accurate staging investigation for gastric cancer. It is poorly-differentiated cancers (both adenocarcinoma and signet-ring cell carcinoma) which have a greater possibility of being inaccurately staged by a preoperative CT-Scan.

\section{KEY WORDS}

Gastric Cancer, Clinicopathological Profile, Preoperative Finding, Peroperative Findings
Corresponding Author:

Dr. Arindam Das,

\#18A, Santosh Roy Road,

Barisha, Kolkata-700008,

West Bengal, India.

E-mail: dasarindam1988@gmail.com

DOI: $10.14260 / j e m d s / 2019 / 717$

Financial or Other Competing Interests: None.

How to Cite This Article:

Das S, Das A. Clinicopathological profile of ca stomach and comparison of preoperative findings with peroperative and histopathological findings. J. Evolution Med. Dent. Sci. 2019;8(44):3302-3308, DOI: $10.14260 /$ jemds/2019/717

Submission 31-07-2019,

Peer Review 25-09-2019,

Acceptance 01-10-2019,

Published 04-11-2019. 


\section{BACKGROUND}

Gastric cancer is the $4^{\text {th }}$ most common cancer in the world ( $9 \%$ of all cancers) after lung, breast and colorectal cancer. Over all, it is the $2^{\text {nd }}$ most common cause of death but in some Asian countries, it is still the $1^{\text {st }}$ common cause of cancer death. ${ }^{1,2,3}$ It is usually seen in patients $>50$ years. ${ }^{4,5}$ Worldwide the incidence of new cases of gastric cancer in 2002 was 934,000 of which $56 \%$ cases were from Asia. Proximal stomach is the commonest site of affection in western countries while distal stomach is more commonly affected in Asian population.6,7 The incidence of gastric carcinoma is decreasing in western countries and increasing in the rest of the world ${ }^{1}$. Though there is a decreasing trend over the past few decades, gastric cancer remains a major public health problem in the world.8,9 Proximal gastric cancer has a more aggressive clinical course than distal ones $\&$ has a poorer prognosis.7,10,11,12 Over all, the commonest histopathological type is adenocarcinoma \& in Asian countries, it is the intestinal type due to intestinal metaplasia. $^{5}$ Surgery is the mainstay of treatment. ${ }^{13,14}$ Majority of the patients present with advanced disease \& their prognosis is very poor despite availability of modern chemotherapeutic regimen. ${ }^{15,16}$ It is also frequently seen in our hospital that patients with preoperatively resectable gastric cancer as per a staging CT-scan of the abdomen are found to have unresectable disease on laparotomy. Therefore, the need remains to evaluate the efficacy of preoperative staging investigations in accurately staging the disease as determined peroperatively and on final histopathological examination. This study addresses the clinicopathological profile- i.e. clinical presentation, preoperative radiological stage, peroperative findings and the final histopathological staging in patients with gastric carcinoma in a tertiary care hospital in Eastern India.

\section{METHODS}

After taking approval from the institutional ethics committee, the study was carried out in the Department of general surgery, SSKM Hospital, Kolkata. All patients with clinical suspicion of carcinoma stomach were included. Patients with tumours histologically other than carcinoma stomach and non-compliant patients reluctant to undergo surgery were excluded. A total of 50 patients were considered. Patients with carcinoma stomach meeting the inclusion and exclusion criteria were prepared, followed up, operated and preoperative, peroperative and final histopathological findings were tallied. Preoperatively, selected patients were subjected to a detailed history, clinical examination, investigations (including upper GI endoscopy, routine blood tests, contrast enhanced CT-scan abdomen), correction of anaemia, dyselectrolytaemia, dehydration and other comorbidities. Peroperatively, findings in respect of location of growth, presence of metastasis, ascites, infiltration into adjoining structures, resectability, preoperative staging were assessed. If resectable, the specimen of gastrectomy and lymph nodes was removed. If unresectable, tissue was taken from the mass for histopathological examination. Postoperatively, the specimen was transported to the pathology department in formalin where tissue was taken from the specimen, slides were prepared, stained with haematoxylin and eosin and final histopathological assessment was done.

\section{Statistical Analysis}

Information was collected according to various pre-defined parameters and was analysed as per standard statistical protocols and tests. For statistical analysis data were entered into a Microsoft excel spreadsheet and then analysed by SPSS 24.0 and GraphPad Prism version 5. Data had been summarized as mean and standard deviation for numerical variables and count and percentages for categorical variables. Two-sample t-tests for a difference in mean involved independent samples or unpaired samples. Paired t-tests were a form of blocking and had greater power than unpaired tests. A chi-squared test ( $\chi 2$ test) was any statistical hypothesis test wherein the sampling distribution of the test statistic is a chi-squared distribution when the null hypothesis is true. Without other qualification, 'chi-squared test' often is used as short for Pearson's chi-squared test. Unpaired proportions were compared by Chi-square test or Fischer's exact test, as appropriate. Z-test (Standard Normal Deviate) was used to test the significant difference of proportions. Explicit expressions that can be used to carry out various t-tests are given below. In each case, the formula for a test statistic that either exactly follows or closely approximates a t-distribution under the null hypothesis is given. Also, the appropriate degrees of freedom are given in each case. Each of these statistics can be used to carry out either a one-tailed test or a two-tailed test. Once a $t$ value is determined, a p-value can be found using a table of values from Student's t-distribution. If the calculated $p$-value is below the threshold chosen for statistical significance (usually the 0.10 , the 0.05 , or 0.01 level), then the null hypothesis is rejected in favour of the alternative hypothesis. p-value $\leq 0.05$ was considered for statistically significant.

\section{RESULTS}

\begin{tabular}{|c|c|c|c|c|c|c|}
\hline & & & & \multicolumn{2}{|c|}{ Lauren's Types } & \multirow[b]{2}{*}{ Total } \\
\hline \multirow{8}{*}{$\begin{array}{c}\text { Age } \\
\text { (in years) }\end{array}$} & Age (Years) & No. & $\%$ & \begin{tabular}{|l|} 
Diffuse \\
\end{tabular} & \multirow{2}{*}{\begin{tabular}{|c|} 
Intestinal \\
0
\end{tabular}} & \\
\hline & $\leq 30$ & 6 & $12.0 \%$ & 6 & & 6 \\
\hline & $31-40$ & 9 & $18.0 \%$ & 6 & 3 & 9 \\
\hline & $41-50$ & 12 & $24.0 \%$ & 6 & 6 & 12 \\
\hline & $51-60$ & 12 & $24.0 \%$ & 0 & 12 & 12 \\
\hline & $61-70$ & 8 & $16.0 \%$ & 0 & 8 & 8 \\
\hline & $>70$ & 3 & $6.0 \%$ & 0 & 3 & 3 \\
\hline & Total & 50 & $100.0 \%$ & $18(36 \%)$ & $32(64 \%)$ & 50 \\
\hline \multirow{3}{*}{ Sex } & Female & 23 & $46.0 \%$ & 12 & 11 & 23 \\
\hline & Male & 27 & $54.0 \%$ & 6 & 21 & 27 \\
\hline & Total & 50 & $100.0 \%$ & 18 & 32 & 50 \\
\hline \multirow{5}{*}{$\begin{array}{l}\text { Macro- } \\
\text { scopical types }\end{array}$} & Infiltrative & 18 & $36.0 \%$ & 18 & 0 & 18 \\
\hline & Ulcerative & 3 & $6.0 \%$ & 0 & 3 & 3 \\
\hline & Ulceroproliferative & 29 & $58.0 \%$ & 0 & 29 & 29 \\
\hline & Polypoidal & 0 & $0.0 \%$ & 0 & 0 & 0 \\
\hline & Total & 50 & $100.0 \%$ & 18 & 32 & 50 \\
\hline \multirow{4}{*}{$\begin{array}{l}\text { Tumour } \\
\text { Grade }\end{array}$} & Poorly differentiated & 28 & $56.0 \%$ & 18 & 10 & 28 \\
\hline & $\begin{array}{c}\text { Moderately } \\
\text { differentiated }\end{array}$ & 15 & $30.0 \%$ & 0 & 15 & 15 \\
\hline & Well differentiated & 7 & $14 \%$ & 0 & 7 & 7 \\
\hline & Total & 50 & $100.0 \%$ & 18 & 32 & 50 \\
\hline \multirow{3}{*}{$\begin{array}{c}\text { Tumour Histo- } \\
\text { pathology }\end{array}$} & Adenocarcinoma & 32 & $64.0 \%$ & 0 & 2 & 32 \\
\hline & $\begin{array}{l}\text { Signet ring cell } \\
\text { carcinoma }\end{array}$ & 18 & $36 \%$ & 18 & 0 & 18 \\
\hline & Total & 50 & $100.0 \%$ & 18 & 32 & 50 \\
\hline
\end{tabular}

Table 1. Distribution of Age, Sex, Macroscopic Types, Tumour Grade and Tumour Histopathology in relation to Lauren's Types 


\begin{tabular}{|c|c|c|c|c|c|}
\hline & & Frequency & $\%$ & Z-value & p-Value \\
\hline \multirow[b]{2}{*}{ Vomiting } & Absent & 9 & $18.0 \%$ & \multirow[b]{2}{*}{6.4} & \multirow[b]{2}{*}{$<.00001$} \\
\hline & Present & 41 & $82.0 \%$ & & \\
\hline \multirow{2}{*}{ Post-prandial fullness } & Absent & 8 & $16.0 \%$ & \multirow{2}{*}{6.8} & \multirow{2}{*}{$<.00001$} \\
\hline & Present & 42 & $84.0 \%$ & & \\
\hline \multirow{2}{*}{ Pain abdomen } & Absent & 23 & $46.0 \%$ & \multirow{2}{*}{0.8} & \multirow{2}{*}{.42372} \\
\hline & Present & 27 & $54.0 \%$ & & \\
\hline \multirow{2}{*}{ Haematemesis and melaena } & Absent & 32 & $64.0 \%$ & \multirow{2}{*}{2.8} & \multirow{2}{*}{.00512} \\
\hline & Present & 18 & $36.0 \%$ & & \\
\hline \multirow{2}{*}{ Weight loss } & Absent & 7 & $14.0 \%$ & \multirow{2}{*}{7.2} & \multirow{2}{*}{$<.00001$} \\
\hline & Present & 43 & $86.0 \%$ & & \\
\hline \multirow{2}{*}{ Anorexia } & Absent & 3 & $6.0 \%$ & \multirow{2}{*}{8.8} & \multirow{2}{*}{$<.00001$} \\
\hline & Present & 47 & $94.0 \%$ & & \\
\hline \multirow{2}{*}{ Dyspepsia } & Absent & 14 & $28.0 \%$ & \multirow{2}{*}{4.4} & \multirow{2}{*}{$<.00001$} \\
\hline & Present & 36 & $72.0 \%$ & & \\
\hline \multirow{2}{*}{ Abdominal tenderness } & Absent & 31 & $62.0 \%$ & \multirow{2}{*}{2.4} & \multirow{2}{*}{.0164} \\
\hline & Present & 19 & $38.0 \%$ & & \\
\hline \multirow{2}{*}{ Anaemia } & Absent & 10 & $20.0 \%$ & \multirow{2}{*}{6.0} & \multirow{2}{*}{$<.00001$} \\
\hline & Present & 40 & $80.0 \%$ & & \\
\hline \multirow{2}{*}{ Palpable mass } & Absent & 32 & $64.0 \%$ & \multirow{2}{*}{2.8} & \multirow{2}{*}{.00512} \\
\hline & Present & 18 & $36.0 \%$ & & \\
\hline \multirow{2}{*}{ Ascites } & Absent & 34 & $68.0 \%$ & \multirow{2}{*}{3.6} & \multirow{2}{*}{.00032} \\
\hline & Present & 16 & $32.0 \%$ & & \\
\hline Palpable left supraclavicular & Absent & 41 & $82.0 \%$ & 64 & <00001 \\
\hline lymph nodes & Present & 9 & $18.0 \%$ & 0.4 & $<.00001$ \\
\hline Table 2. $\mathrm{L}$ & ibutio & $m p$ & and & $n s$ & \\
\hline
\end{tabular}

\begin{tabular}{|c|c|c|c|c|c|c|}
\hline & CT-Scan Staging & \multicolumn{4}{|c|}{ Peroperative Staging } & \multirow[b]{2}{*}{ Total } \\
\hline \multirow{19}{*}{ T- Stage } & CT T & $\mathbf{T}_{2}$ & $\mathbf{T}_{3}$ & $\mathbf{T}_{4 \mathbf{a}}$ & $\mathbf{T}_{4 \mathrm{~b}}$ & \\
\hline & $T_{0}$ & 1 & 0 & 0 & 0 & 1 \\
\hline & Row \% & 100.0 & 0.0 & 0.0 & 0.0 & 100.0 \\
\hline & Col \% & 50.0 & 0.0 & 0.0 & 0.0 & 2.0 \\
\hline & $\mathbf{T}_{2}$ & 1 & 0 & 0 & 0 & 1 \\
\hline & Row \% & 100.0 & 0.0 & 0.0 & 0.0 & 100.0 \\
\hline & Col \% & 50.0 & 0.0 & 0.0 & 0.0 & 2.0 \\
\hline & $\mathbf{T}_{3}$ & 0 & 4 & 7 & 13 & 24 \\
\hline & Row \% & 0.0 & 16.7 & 29.2 & 54.2 & 100.0 \\
\hline & $\mathrm{Col} \%$ & 0.0 & 100.0 & 30.4 & 61.9 & 48.0 \\
\hline & $\mathrm{T}_{4 \mathrm{a}}$ & 0 & 0 & 15 & 6 & 21 \\
\hline & Row \% & 0.0 & 0.0 & 71.4 & 28.6 & 100.0 \\
\hline & Col \% & 0.0 & 0.0 & 65.2 & 28.6 & 42.0 \\
\hline & $\mathrm{T}_{4 \mathrm{~b}}$ & 0 & 0 & 1 & 2 & 3 \\
\hline & Row \% & 0.0 & 0.0 & 33.3 & 66.7 & 100.0 \\
\hline & Col \% & 0.0 & 0.0 & 4.3 & 9.5 & 6.0 \\
\hline & Total & 2 & 4 & 23 & 21 & 50 \\
\hline & Row \% & 4.0 & 8.0 & 46.0 & 42.0 & 100.0 \\
\hline & Col \% & 100.0 & 100.0 & 100.0 & 100.0 & 100.0 \\
\hline & \multicolumn{6}{|c|}{ Peroperative N } \\
\hline \multirow{13}{*}{$\mathrm{N}$-Stage } & CT N & $\mathrm{N}_{0}$ & $\mathrm{~N}_{1}$ & $\mathbf{N}_{2}$ & $\mathbf{N}_{3}$ & TOTAL \\
\hline & $\mathrm{N}_{0}$ & 12 & 11 & 8 & 4 & 35 \\
\hline & Row \% & 34.3 & 31.4 & 22.9 & 11.4 & 100.0 \\
\hline & Col \% & 100.0 & 64.7 & 50.0 & 80.0 & 70.0 \\
\hline & $\mathrm{N}_{\mathbf{1}}$ & 0 & 6 & 7 & 0 & 13 \\
\hline & Row \% & 0.0 & 46.2 & 53.8 & 0.0 & 100.0 \\
\hline & $\mathrm{Col} \%$ & 0.0 & 35.3 & 43.8 & 0.0 & 26.0 \\
\hline & $\mathbf{N}_{2}$ & 0 & 0 & 1 & 1 & 2 \\
\hline & Row \% & 0.0 & 0.0 & 50.0 & 50.0 & 100.0 \\
\hline & Col \% & 0.0 & 0.0 & 6.3 & 20.0 & 4.0 \\
\hline & Total & 12 & 17 & 16 & 5 & 50 \\
\hline & Row \% & 24.0 & 34.0 & 32.0 & 10.0 & 100.0 \\
\hline & Col \% & 100.0 & 100.0 & 100.0 & 100.0 & 100.0 \\
\hline & \multicolumn{6}{|c|}{ Peroperative M } \\
\hline \multirow{10}{*}{ M-Stage } & CT M & $\mathbf{M}_{0}$ & \begin{tabular}{|l|}
$\mathbf{M}_{1}$ \\
\end{tabular} & \multicolumn{3}{|c|}{ TOTAL } \\
\hline & $M_{0}$ & 33 & 14 & \multicolumn{3}{|c|}{47} \\
\hline & Row \% & 70.2 & 29.8 & \multirow{2}{*}{\multicolumn{3}{|c|}{$\begin{array}{c}100.0 \\
94.0\end{array}$}} \\
\hline & Col \% & 100.0 & 82.4 & & & \\
\hline & $\mathbf{M}_{1}$ & 0 & 3 & \multicolumn{3}{|c|}{3} \\
\hline & Row \% & 0.0 & 100.0 & \multicolumn{3}{|c|}{100.0} \\
\hline & Col \% & 0.0 & 17.6 & \multicolumn{3}{|c|}{6.0} \\
\hline & Total & 33 & 17 & \multirow{2}{*}{\multicolumn{3}{|c|}{$\begin{array}{c}50 \\
100.0\end{array}$}} \\
\hline & Row \% & 66.0 & 34.0 & & & \\
\hline & Col \% & 100.0 & 100.0 & \multicolumn{3}{|c|}{$\begin{array}{l}100.0 \\
100.0 \\
\end{array}$} \\
\hline \multicolumn{7}{|c|}{$\begin{array}{l}\text { Table 3. Distribution of TNM. Staging and Comparison } \\
\text { between CT-Scan Staging and Peroperative Staging }\end{array}$} \\
\hline
\end{tabular}

\begin{tabular}{|c|c|c|}
\hline Operation Performed & Frequency & Percent \\
\hline Distal Gastrectomy & 9 & $18.0 \%$ \\
\hline Feeding Jejunostomy & 20 & $40.0 \%$ \\
\hline Gastrojejunostomy & 2 & $4.0 \%$ \\
\hline Subtotal Gastrectomy & 9 & $18.0 \%$ \\
\hline Total Gastrectomy & 10 & $20.0 \%$ \\
\hline Total & $\mathbf{5 0}$ & $\mathbf{1 0 0 . 0} \%$ \\
\hline Table 4. Distribution of Surgeries Performed \\
\hline
\end{tabular}

\begin{tabular}{|c|c|c|c|}
\hline \multicolumn{4}{|c|}{ Grade } \\
\hline $\begin{array}{c}\text { Palliative Operation } \\
\text { Performed }\end{array}$ & $\begin{array}{c}\text { Moderately } \\
\text { Differentiated }\end{array}$ & $\begin{array}{c}\text { Poorly } \\
\text { Differentiated }\end{array}$ & Total \\
\hline FJ & 1 & 19 & 20 \\
Row $\%$ & 5.0 & 95.0 & 100.0 \\
Col \% & 50.0 & 95.0 & 90.9 \\
\hline GJ & 1 & 1 & 2 \\
Row $\%$ & 50.0 & 50.0 & 100.0 \\
Col \% & 50.0 & 5.0 & 9.1 \\
\hline TOTAL & 2 & 20 & 22 \\
Row \% & 9.1 & 90.9 & 100.0 \\
Col \% & 100.0 & 100.0 & 100.0 \\
\hline
\end{tabular}

Table 5. Distribution of Palliative Surgeries Performed vs Grade FJ: Feeding jejunostomy GJ: Gastrojejunostomy

\section{DISCUSSION}

Carcinoma stomach is the $4^{\text {th }}$ most common cancer in the world after lung, breast and colorectal cancer $(9 \%$ of all cancers according to a study of Clinicopathological Features of Gastric Cancer: A Study based on Cancer Registry Data by Safee A, Moghimi-Dehkordi B, Fatemi SR et al in Iran. Now it is the $2^{\text {nd }}$ most common cancer causing death worldwide superseded by only lung cancer ${ }^{17,18}$ but in Japan and in Asian countries, it is still the most common cause of death according to a study by Parker SL, Tong T, Bolden S et al [1997] and Curtis RE, Kennedy BJ, Myers MH et al[1985]. The incidence, site, aggression and prognosis of gastric cancer vary considerably in different parts of the world. ${ }^{19,20}$ In this study, an attempt was made to study the different clinical features, pathological types, comparison of the preoperative CT-scan staging with the peroperative and final histopathological staging, different surgical treatments received by the patients according to stage.

\section{Age Incidence}

In this study, total of 50 patients were included. Amongst them, $54 \%$ are aged <= 50 years which in some reports is $14.8 \% 1,2,19,20$ and $46 \%$ are $>50$ years of age. Mean Age of presentation is 49.12 years. Peak Incidence is found in the Age Group of 41-60 years and least incidence is found in the age group $>70$ years. This trend corroborates with the global trend that worldwide, gastric cancer is shifting more towards the young as supported by a study by Kim DY, Ryu SY, Kim YJ et al. ${ }^{21}$

\section{Sex Incidence}

In some published series, male female ratio is $2: 1.1,2,16,19,20,21,22$ In this study, $54 \%$ of the patients were male and the rest were female and the ratio is 1.17.

\section{Clinical Presentation}

In a study in Khuzestan, the two most common presentations are weight loss and abdominal pain. ${ }^{21,23}$ In a study done by Kabir et al, abdominal pain (100\%), vomiting (78\%), dysphagia $(24 \%)$ and weight loss $(62 \%)$ were predominant symptoms pertaining to gastric carcinoma. ${ }^{24}$ Interview of 18,365 patients by the American college of surgeons, common presentations were weight loss (66.6\%), abdominal pain (51.6\%), nausea/vomiting (34\%) and melaena (20.2\%). Again Qurieshi et al showed common presenting symptoms as weight loss (35\%), dyspepsia (76\%), anorexia (35\%) and vomiting (35.8\%). ${ }^{25}$ Saha et al in their study showed that abdominal pain $(66.2 \%)$ was the commonest symptom 
followed by weight loss (43.3\%), indigestion (45.9\%), anorexia (39.9\%), nausea/vomiting (34.2\%), postprandial pain (29\%) and melaena $(9.5 \%){ }^{26}$ In this study, the commonest symptom was anorexia (94\%) followed by weight loss (86\%) with z-scores of 8.8 and 7.2 and were thus, statistically significant. Of the symptoms pertaining to gastric outlet obstruction, vomiting and post-prandial fullness were present in $82 \%$ and $84 \%$ of the cases with z-scores of 6.4 and 6.8 respectively indicating their significance. The most common sign was anaemia (Present in $80 \%$ of the cases) with a z-value of 6.0. Although palpable left supraclavicular lymph nodes were present in $18 \%$ of the cases, it had a z-value of 6.4 and was thus highly significant.

\section{Site of Lesion}

Worldwide, the site of gastric cancer is changing in the western world. Incidence of distal gastric cancer is decreasing, and proximal gastric cancer is increasing (41\% and $50 \%$ respectively) ${ }^{27,28}$ Recent study from Kerala in India showed that though the predominant site of cancer was the antral mucosa, there was a trend towards proximal shift. Qurieshi et al showed that in the Kashmiri population, incidences of cancer in proximal, mid and distal stomach were $42 \%, 6.2 \%$ and $45.7 \%$ respectively. ${ }^{25}$ Afridi et al reported growth at the cardiac end in 33\%, pylorus and antrum in $40 \%$, linitis plastica in $13.3 \%$ and only body and body and pylorus in $6.7 \%$ of the patients. ${ }^{29}$ In this study, the most common site of involvement was the antrum (38\%). The body and antrum were involved in $22 \%$ of the cases. Diffuse involvement was seen in $36 \%$ of the cases with $6 \%$ of the cases having spread to and beyond the esophagogastric junction. The antrum, body and cardia were involved in $34 \%$ of the cases (30\% diffuse and $4 \%$ intestinal type).

\section{Macroscopical Types}

Macroscopically, gastric cancer has been classified into 4 types- Type I: polypoidal lesion, Type II: Fungating lesion, Type III: Ulcerated lesion and Type IV: infiltrating lesion on the gastric wall or linitis plastica. But, there is considerable overlap between the above different types. Qurieshi et al showed $35.5 \%$ ulceroproliferative, $26 \%$ proliferative, $31 \%$ ulcerative and $7.4 \%$ infiltrative lesions during endoscopic procedure performed in Kashmiri patients. ${ }^{25}$ Another study by Kabir et al showed that ulcerative lesion was $56 \%$, ulceroproliferative lesion $10 \%$ and polypoidal lesion $34 \% .24$ In this study, the most common type was ulceroproliferative (58\%) followed by infiltrative (36\%). The least common was ulcerative $(6 \%)$ while the polypoidal type was not found. The infiltrative type was present in all cases of diffuse gastric cancer.

\section{Stage at Presentation}

Kim et $\mathrm{al}^{21}$ reported that $80.3 \%$ young patients presented with advanced gastric carcinoma. In a Middle Eastern study, two-thirds of the patients presented with advanced gastric cancer. But in another study, early gastric cancer is more common in young age group than their older counterpart (19.7\% vs $13.8 \%)$. In this study, $2 \%, 2 \%, 48 \%, 42 \%, 6 \%$ of the patients presented with $\mathrm{T} 0, \mathrm{~T} 2, \mathrm{~T} 3, \mathrm{~T} 4 \mathrm{a}, \mathrm{Tb}$ stage on CTScan. $70 \%, 26 \%, 4 \%$ of the patients had N0, N1, N2 stage on CT-Scan. $94 \%$ of the patients had M0 disease while only $6 \%$ had M1 disease on CT-Scan. Peroperatively, 4\% T2, 8\% T3, $46 \% \mathrm{~T} 4 \mathrm{a}, 42 \% \mathrm{~T} 4 \mathrm{~b}$ were the relative percentages of $\mathrm{T}$-stages found. $24 \%, 34 \%, 32 \%, 10 \%$ of the patients had NO, N1, N2, N3 lymph nodal staging respectively. $66 \%$ had M0 disease while $34 \%$ had metastases and were grouped as M1. In this study, all $(100 \%)$ of the patients presented with advanced gastric cancer on histopathology. 4\% T2, 8\% T3, 46\% T4a, $42 \% \mathrm{~T} 4 \mathrm{~b}$ were the relative percentages of $\mathrm{T}$-stages found. $24 \%, 34 \%, 32 \%, 10 \%$ of the patients had NO, N1, N2, N3 lymph nodal staging respectively. $64 \%$ had M0 disease while $36 \%$ had metastases and were grouped as M1.

\section{Association between Preoperative and Peroperative Staging}

The only potential curative therapy is surgical resection. For effective curative treatment, there must be complete resection of all gross disease with no residual microscopic disease. Accurate preoperative staging of gastric cancer is important in planning most effective therapy towards cure or palliation. ${ }^{30}$ The depth of intramural tumour invasion and spreading beyond the gastric wall, the involvement of lymph nodes and distant metastases are the most important prognostic factors in gastric cancer. ${ }^{31}$ Most patients present with advanced disease at diagnosis, so they could not be considered suitable for resection. In these patients, it is relevant to have a sensitive imaging tool for detection and thus avoid the morbidity of an unnecessary laparotomy. ${ }^{32,33}$ "Imaging techniques" have assumed greater clinical value in the further assessment of an endoscopically or radiologically verified neoplastic lesion of the stomach through the ability to evaluate its extent of invasion, metastatic involvement of lymph nodes and/or distant organs. ${ }^{34}$ Because the aim of gastric cancer surgery is to excise the primary lesion adequately, it is very important to know the location of this lesion and the tumour margin before any therapeutic decision can be taken. In this context, the role of CT-Scan in the preoperative staging of gastric cancer has been suggested as an accurate imaging modality for evaluating the extent of primary gastric cancer and nodal involvement of the disease. $35,36,37$ However, reported results comparing preoperative CT with histopathological findings are variable. ${ }^{38,39}$ Controversy exists as to the value of CT-Scan in the preoperative staging of gastric cancer, because of its limited ability to identify correctly lymph node metastases, invasion of adjacent organs or hepatic and peritoneal metastases. ${ }^{40}$ [The surgery clinic Nis Clinical Centre analysed the clinical data of 65 gastric cancer patients and found that in $38 \%$ of them, preoperative and intraoperative findings coincided. In $60 \%$, a higher level of gastric cancer was identified while in $2 \%$, it is lower.] ${ }^{41}$ [Yet, another study reported that the overall accuracy of CT-staging and operability assessment was $72 \%$ and $82 \%$ respectively. Perigastric fat involvement had a positive predictive value of 91\%.The demonstration of local lymph node involvement and adjacent organs was unreliable.] ${ }^{60}$ Thus, although multiple studies testing the accuracy of CT-scanning in preoperative staging of patients with gastric adenocarcinoma have been carried out, the results are controversial. 42

According to Lee et $\mathrm{al}^{43}$, helical CT with two-phase scanning, particularly the mucosal phase (38-45 seconds), is effective for identifying the unique enhancement patterns of early gastric cancer. Takao et $\mathrm{al}^{44}$ showed that the earlier 
phase (45 seconds) is accurate for determining the depth of tumor invasion through the wall; the later phase ( 3 minutes) did not provide additional information. Cancers on the superior or inferior wall of the gastric antrum are difficult to detect and to stage correctly because of poor z-axis resolution and partial-volume averaging effects 44,45. For transverse colon or mesocolon invasion, Andaker et $\mathrm{al}^{46}$ reported a sensitivity of $25 \%$ by using incremental CT. By using singledetector row helical CT, Davies et al ${ }^{47}$ reported improved sensitivity (76\%) and specificity (95\%).For tumor invasion of the pancreas, the previously reported sensitivity and specificity of CT ranged from $33 \%$ to $100 \%$ and from $77 \%$ to $99 \%$, respectively $48,49,50$ The loss of the intervening fat plane does not necessarily imply invasion, and it has been reported that even the presence of an indistinct interface between the two organs is not a reliable sign of invasion, because an inflammatory adhesion can mimic true invasion. ${ }^{51}$ Additional scanning in the decubitus position, on the patient's right side, often is used to reduce a false-positive diagnosis of pancreatic invasion by observing a change in the relative location of the gastric tumour and the pancreas. In this study, it was seen that T-stage was lower in $54 \%$ and higher in $2 \%$ of cases on CT-scan. N-stage was found to be lower in $62 \%$ of cases respectively on CT-scan in comparison to the peroperative findings. M-stage was under-staged in $28 \%$ of the cases, particularly those having peritoneal deposits. The accuracy of $\mathrm{T}, \mathrm{N}, \mathrm{M}$ staging on CT-scan was $44 \%, 38 \%$ and $72 \%$ respectively.

\section{Lauren's Types}

The Histological classification of gastric carcinoma is based on Lauren's criteria, which describes that gastric carcinoma is of two major subtypes: INTESTINAL and DIFFUSE. Third type, mixed type (Indeterminate type) is another variant. Relative frequencies are approximately 54\% for intestinal type, 32\% for diffuse type and $15 \%$ for indeterminate type. ${ }^{52}$ Regarding histopathological diagnosis, Afridi et al that two-thirds of the patients $(66.6 \%)$ had diffuse subtype, $20 \%$ had intestinal subtype and $13.3 \%$ had gastric lymphoma. ${ }^{29}$ In this study, $64 \%$ of the patients had intestinal type while $36 \%$ had diffuse type. The patients with diffuse type were $\leq 50$ years of age and one-third of the patients were $\leq 30$ years of age while the peak incidence of intestinal type was in the age group of 5160 years $(37.5 \%)$. The findings were significant with a pvalue of $<0.0001$. The findings are in concordance with the global trend that diffuse type is more common in the younger age group in contrast to intestinal which is more common in older age groups. Diffuse type gastric cancer is more common in young patients, in whom there is a female preponderance, 53 and behaves more aggressively than the intestinal type. The male: female ratio in patients with diffuse type was 1:2 whereas it was 1.9:1 for the intestinal type. Thus, this study has shown that the incidence of diffuse type is more in females while that of intestinal is more in males $(p=0.02787)$ which again matches with the global trend.

\section{Surgery Done}

Optimal surgical therapy offered to a patient with resectable proximal gastric carcinoma is total gastrectomy and to a patient with distal gastric cancer is distal gastrectomy both of which are curative surgery. ${ }^{54,55,56,57}$ In case of metastatic cancer, palliative surgery may be done which are palliative gastrojejunostomy ${ }^{54,55,56,57}$ or at least feeding jejunostomy. In this study, this protocol is followed. $40 \%$ of the patients underwent a palliative feeding jejunostomy, $4 \%$ of the patients underwent a palliative gastrojejunostomy. Total gastrectomy was done in $20 \%$, subtotal gastrectomy in $18 \%$, distal gastrectomy in $18 \%$ of the patients.

\section{Histopathology}

Nakamura et al have shown that poorly-differentiated adenocarcinoma was the commonest histological type in their study which are mostly advanced gastric cancer. But in early gastric cancer, well-differentiated adenocarcinoma was the commonest type (45.5\%). In this study, $56 \%$ of the patients had poorly differentiated tumours (Including both poorlydifferentiated adenocarcinoma and signet ring carcinoma), $30 \%$ had moderately-differentiated tumours and $14 \%$ had well-differentiated tumours. $64 \%$ of the patients had adenocarcinoma and 36\% had signet-ring carcinoma. Signetring cell carcinoma was found in all the cases of diffuse gastric cancer which is in accordance with global data.

\section{Association between the Tumour Grade and the Operation Performed \\ Of the 22 patients (44\%) who underwent palliative procedures for metastatic disease, $90.9 \%$ had poorly- differentiated tumours (including signet-ring cell type) and only $9.1 \%$ had moderately-differentiated tumour. Of the 28 patients with poorly-differentiated tumours, 20(i.e. 71.43\%) had metastatic disease and underwent palliative procedures. 2 of the 15 patients (i.e. 13.3\%) with moderately- differentiated tumours underwent palliative procedures for metastatic disease.}

\section{CONCLUSIONS}

Although CT-Scan is a very commonly used preoperative staging investigation for gastric cancer, in our study we found that the accuracy of CT-Scan in T, N, M staging was 44\%, 38\% and $72 \%$ respectively. The disparity between preoperative staging and preoperative findings was more in case of poorly differentiated cancers. Hence, more advanced staging investigations like endoscopic ultrasound are needed for more accurate preoperative staging.

\section{ACKNOWLEDGEMENT}

We are grateful to Dr. Samiran Samanta, R. M. O., Department of Radiology, SSKM Hospital, Kolkata, Dr. Anup Sarkar, PostDoctoral trainee, Department of Gastroenterology, SSKM Hospital, Kolkata and Dr. Keya Basu Ghosh, Associate Professor, Department of Pathology, SSKM Hospital, Kolkata, for their help and support. 


\section{REFERENCES}

[1] Pisani P, Parkin DM, Bray F, et al. Estimates of the worldwide mortality from 25 cancers in 1990. Int J Cancer 1999;83(1):18-29.

[2] Parker SL, Tong T, Bolden S, et al. Cancer statistics, 1997. CA Cancer J Clin 1997;47(1):5-27.

[3] Curtis RE, Kennedy BJ, Myers MH, et al. Evaluation of AJC stomach cancer staging using the SEER population. Semin Oncol 1985;12(1):21-31.

[4] Medina-Franco H, Heslin MJ, Cortes-Gonzalez R. Clinicopathological characteristics of gastric carcinoma in young and elderly patients: a comparative study. Ann Surg Oncol 2000;7(7):515-9.

[5] Crew KD, Neugut AL. Epidemiology of gastric cancer. World J Gastroenterol 2006:12(3):354-62.

[6] Parkin DM, Bray F, Ferlay J, et al. Global cancer statistics 2002. CA Cancer J Clin 2005;55(2):74-108.

[7] Blot WJ, Devesa SS, Kneller RW, et al. Rising incidence of adenocarcinoma of the esophagus and gastric cardia. JAMA 1991;265(10):1287-9.

[8] Inoue M, Tsugane S. Epidemiology of gastric cancer in Japan. Postgrad Med J 2005;81(957):419-24.

[9] Ferlay J, Bray F, Pisani P, et al. GLOBOCAN 2002: cancer incidence, mortality and prevalence worldwide, Version 2.0 IARC Cancer Base no 5, Lyon: IARC Press 2004. http://www-depdb.iarc.fr/globocan2002.htm.

[10] Brown LM, Devesa SS. Epidemiological trends in esophageal and gastric cancer in the United States. Surg Oncol Clin North Am 2002;11(2):235-56.

[11] Devesa SS, Blot WJ, Fraumeni JF. Changing patterns in the incidence of esophageal and gastric carcinoma in the United States. Cancer 1998;83(10):2049-53.

[12] Craanen ME, Dekker W, Blok P, et al. Time trends in gastric carcinoma: changing patterns of type and location. Am J Gastroenterol 1992;87(5):572-9.

[13] Bonenkamp JJ, Hermans J, Sasako M. Extended lymph node dissection for gastric cancer. $\mathrm{N}$ Engl J Med 1999;340(12):908-14.

[14] Kodama Y, Sugimachi K, Soejima K, et al. Evaluation of extensive lymph node dissection for carcinoma of the stomach. World J Surg 1981;5(2):241-8.

[15] Icli F, Celik I, Aykan F, et al. A randomized phase III trial of etoposide, epirubicin and cisplatin versus 5fluorouracil, epirubicin and cisplatin in the treatment of patients with advanced gastric carcinoma. Cancer 1998;83(12):2475-80.

[16] Ajani JA, Van Custem E, Moiseyenko FC, et al. Docetaxel, cisplatin, 5-fluorouracil compared to cisplatin and 5fluorouracil for chemotherapy-naive patients with metastatic or locally recurrent, unresectable gastric carcinoma. Interim results of a randomized phase III trial (V325). Proc Am Soc Clin Oncol 2003;22:999.

[17] Schwartz RE, Karpeh MS, Brennan MF. Surgical management of gastric cancer: The Western experience. In: Hennessy PJ, Daly JM, Reynolds JV, eds. Management of upper gastrointestinal cancer. New York: Harcourt Brace 1999:84-107.

[18] Charlton A, Blair V, Shaw D, et al. Hereditary diffuse gastric cancer: predominance of multiple foci of signet ring cell carcinoma in distal stomach and transitional zone. Gut 2004;53(6):814-20.

[19] Sasagawa T, Solano H, Mena F. Gastric cancer in Costa Rica. Gastrointes Endosc 1999;50(4):594-5.

[20] Yao JC, Tseng JF, Worah S, et al. Clinicopathologic behavior of gastric adenocarcinoma in Hispanic patients: analysis of a single institution's experience over 15 years. J Clin Oncol 2005;23(13):3094-103.

[21] Kim DY, Ryu SY, Kim YJ, et al. Clinicopathological characteristics of gastric carcinoma in young patients. Langenbecks Arch Surg 2003;388(4):245-9.

[22] Sadjadi A, Malekzadeh R, Derakhshan MH, et al. Cancer occurrence in Ardabil: result of a population-based registry from Iran. Int J Cancer 2003;107(1):113-8.

[23] Eskandar H, Hossein SS, Rahim M, et al. Clinical profile of gastric cancer in Khuzestan, southwest of Iran. World J Gastroenterol 2006;12(30):4832-5.

[24] Kabir MA, Barua R, Masud H, et al. Clinical presentation, histological findings and prevalence of Helicobacter pylori in patients of gastric carcinoma. Faridpur Medical College Journal 2011;6(2):78-81.

[25] Qurieshi MA, Masoodi MA, Kadla SA, et al. Gastric cancer in Kashmir. Asian Pac J Cancer Prev 2011;12(1):303-7.

[26] Saha AK, Maitra S, Hazra SC. Epidemiology of gastric cancer in the gangetic areas of west Bengal. ISRN Gastroenterol 2013;2013:823483.

[27] Blot WJ, Devesa SS, Kneller RW, et al. Rising incidence of adenocarcinoma of the esophagus and gastric cardia. JAMA 1991;265(10):1287-9.

[28] Hansson LE, Sparen P, Nyren O. Increasing incidence of both major histological types of esophageal carcinomas among young men in Sweden. Int J Cancer 1993;54(3):402-7.

[29] Afridi SP, Bano F, Shafiq-ur-Rahman. Pattern and presentation of carcinoma stomach. J Coll Physicians Surg Pak 2011;21(3):161-3.

[30] Tunaci M. Carcinoma of stomach and duodenum: radiologic diagnosis and staging. Eur J Radiol 2002;42(3):181-92.

[31] Kim AY, Kim HJ, Ha HK. Gastric Cancer by multidetector row CT: preoperative staging. Abdom Imaging 2005;30(4):465-72.

[32] Allum WH, Powell DJ, McConkey CC, et al. Gastric cancer: a 25-year review. Br J Surg 1989;76(6):535-40.

[33] Lundh G, Burn JI, Kolig G, et al. A co-operative international study of gastric cancer (under the auspices of International Federation of Surgical Colleges). Ann R Coll Surg Engl 1974;54(5):219-28.

[34] Zompetta C, Catarci M, Polettini E, et al. Diagnostic accuracy of computerized tomography. Preoperative staging of gastric cancer. Clin Ter 1995;146(12):825-41.

[35] Moss AA, Schnyder P, Marks W, et al. Gastric adenocarcinoma: a comparison of the accuracy and economics of staging by computed tomography and surgery. Gastroenterology 1981;80(1):45-50.

[36] Dehn TC, Reznek RH, Nockler IB, et al. The preoperative assessment of advanced gastric cancer by computed tomography. Br J Surg 1984;71(6):412-7.

[37] Vallgren S, Hedenbro J, Gotberg S, et al. Preoperative computed tomography for evaluation of tumour growth in patients with gastric cancer. Acta Chir Scand 1985;151(6):571-3. 
[38] Fraser J, Nash R, James DC. Computed tomography in gastric cancer. Br J Surg 1985;72(3):249-50.

[39] Cook AO, Levine BA, Sirinek KR, et al. Evaluation of gastric adenocarcinoma. Abdominal tomography does not replace celiotomy. Arch Surg 1986;121(5):603-6.

[40] Davies J, Chalmers AG, Sue-Ling HM, et al. Spiral computed tomography and operative staging of gastric carcinoma: a comparison with histopathological staging. Gut 1997;41(3):314-9.

[41] Zlatic AV, Radojkovic M, Ignjatovic N, et al. The role of preoperative staging of gastric cancer in planning radical surgical treatment. Series: Medicine and Biology 2006;13(1):19-24.

[42] Una E, Jimenez I. Preoperative computed tomography in gastric cancer: does it work? International Society of Gastrointestinal Oncology 2009. Gastrointestinal Oncology Conference October 1-3, 2009.

[43] Lee JH, Jeong YK, Kim DH, et al. Two phase helical CT for detection of early gastric carcinoma: importance of the mucosal phase for analysis of the abnormal mucosal layer. J Comput Assist Tomogr 2000;24(5):777-82.

[44] Takao M, Fukuda T, Iwanga S, et al. Gastric cancer: evaluation of triphasic spiral $\mathrm{CT}$ and radiologic pathologic correlation. J Comput Assist Tomogr 1998;22(2):288-94.

[45] Hundt W, Braunschweig R, Reiser M. Assessment of gastric cancer: value of breath-hold technique and twophase spiral CT. Eur Radiol 1999;9(1):68-72.

[46] Andaker L, Morales O, Hojer H, et al. Evaluation of preoperative computed tomography in gastric malignancy. Surgery 1991;109(2):132-5.

[47] Davies J, Chalmers AG, Sue-Ling HM, et al. Spiral computed tomography and operative staging of gastric carcinoma: a comparison with histopathological staging. Gut 1997;41(3):314-9.
[48] Minami M, Kawauchi N, Itai $\mathrm{Y}$, et al. Gastric tumors: radiologic pathologic correlation and accuracy of $\mathrm{T}$ staging with dynamic CT. Radiology 1992;185(1):173-8.

[49] Tsuburaya A, Noguchi Y, Matsumoto A, et al. A preoperative assessment of adjacent organ invasion by stomach carcinoma with high resolution computed tomography. Surg Today 1994;24(4):299-304.

[50] Adachi Y, Sakino I, Matsumata T, et al. Preoperative assessment of advanced gastric carcinoma using computed tomography. Am J Gastroenterol 1997;92(5):872-5.

[51] Shirakawa T, Fukuda K, Tada S. New method for evaluation of perigastric invasion of gastric cancer by right lateral position CT. Eur Radiol 1996;6(3):358-61.

[52] Mathew A, Gangadharan P, Varghese C, et al. Diet and stomach cancer: a case-control study in South India. Eur J Cancer Prev 2000;9(2):89-97.

[53] Kaneko S, Yoshimura T. Time trend analysis of gastric cancer incidence in Japan by histological types, 19751989. Br J Cancer 2001;84(3):400-5.

[54] Harrison LE, Karpeh MS, Brennan MF. Proximal gastric cancers resected via a trans-abdominal-only approach. Results and comparisons to distal adenocarcinomas of the stomach. Ann Surg 1997;225(6):678-85.

[55] Ito H, Clancy TE, Osteen RT, et al. Adenocarcinoma of the gastric cardia: what is the optimal surgical approach? J Am Coll Surg 2004;199(6):880-6.

[56] Martin RC, Jaques DP, Brennan MF, et al. Extended local resection for advanced gastric cancer: increased survival versus increased morbidity. Ann Surg 2002;236(2):15965.

[57] Buhl K, Schlag P, Herfarth C. Quality of life and functional results following different types of resection for gastric carcinoma. Eur J Surg Oncol 1990;16(4):404-9. 